DOI 10.37882/2223-2982.2020.04.20

\title{
ОПТИМИЗАЦИЯ ПСИХОФИЗИОЛОГИЧЕСКИХ КОНСТРУКТОВ В СТРУКТУРЕ ПРОГРАММЫ РЕАБИЛИТАЦИИ БОЛЬНЫХ ИНСУЛЬТОМ
}

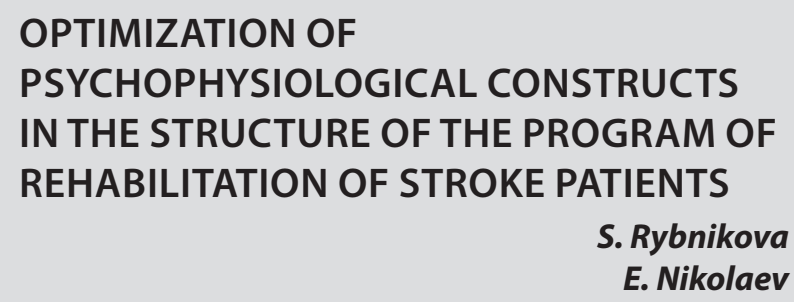

Summary: The analysis of literary data concerning issues of psychology of rehabilitation of stroke patients was carried out. The author conducted a study assessing the need to differentiate the directions of psychological assistance to patients with different localisation of the lesion focus. The author emphasizes that disorders caused by stroke need competent psychological assistance. It is proposed to pay attention to the integration of psychophysiological constructs during the development of correction programs.

Keywords: stroke, stroke patients, rehabilitation, psychological rehabilitation.

\author{
Рыбникова Светлана Михайловна, \\ аспирант, Чувашский государственный университет \\ имени И.Н. Ульянова, г. Чебоксары, \\ rybnikova_sm@mail.ru \\ Николаев Евгений Львович, \\ Д.м.н., профессор, Чувашский государственный \\ университет имени И.Н. Ульянова, г. Чебоксары
}

Аннотация: Проведен анализ литературных данных, касающихся вопросов психологии реабилитации инсультных пациентов. Автором проведено исследование, оценивающее необходимость дифференцировать направления психологической помощи больным с различной локализацией очага поражения. Автором подчеркивается, что нарушения, вызванные инсультом, нуждаются в грамотной психологической помощи. Предлагается, при разработке программ коррекции, уделить внимание моделированию психофизиологических конструктов.

Ключевые слова: инсульт, инсультные пациенты, реабилитация, психологическая реабилитация.
$\mathrm{P}$ еабилитация больного человека представляет собой многовековую проблему, однако вместе со становлением современного человека нарастает его зависимость от новых факторов его бытия и многогранной деятельности, приводящей часто к новым формам заболеваний. Одним из феноменов, перечёркивающих нормальную жизнедеятельность человека, является инсульт, проявляющий себя не только как нарушение мозгового кровоснабжения, но и физическое разрушение коры головного мозга, деформация её структуры. Известно, что это заболевание проявляло себя как результат разрушения кровеносных сосудов в различной форме. Диалектический подход к этой проблеме подсказывает, что для предотвращения или избавления человека от инсульта, прежде всего, надо выяснить его причину, далее, осмыслить механизм его проявления в психофизиологической деятельности человека и научиться выявлять и упреждать тенденции развития, прогрессирования заболевания. Все три перечисленных момента исследования проблемы инсульта отвечают целостному принципу системности необходимой медикосоциальной помощи человеку в условиях напряжённой его жизнедеятельности, приводящей к поражению центральной нервной системы, а как следствие этого - психо-физиологические функциональные расстройства. Проявляется это в виде потери трудоспособности, инвалидности. Одной из важных психосоциальных задач, связанных с людьми, перенесшими инсульт, является их реабилитация и возвращение к нормальной жизнедеятельности.

Мы полагаем, что арсенал методов восстановления, несмотря на свой широкий спектр и богатое содержание, требует дальнейшего наращивания, поскольку картина инсультного проявления, с возрастанием научно-инструментальных возможностей современной медицины, раскрывает новые аспекты природы инсульта. Особенно актуальным на наш взгляд является системный анализ психофизиологического фактора реабилитации.

Целью исследования является моделирование психофизиологических конструктов, встраиваемых в программу восстановления, позволяющих выявить их функциональные связи с факторами реабилитации деятельности мозга, рассматриваемого как высшая психическая форма, результат функционирования и взаимодействия двух полушарий в контексте решения задач нейропсихологической реабилитации.

Для достижения цели необходимо решить следующие задачи.

1. Осмыслить и предложить различные модели психофизиологических конструктов. Определить исследуемые параметры.

2. Экспериментально исследовать выбранные кон- 
структы на предмет выявления связи с факторами реабилитации деятельности мозга на уровне высших психических форм

3. Показать результаты влияния конструктов левого полушария и правого полушария по отдельности и во взаимодействии на результаты реабилитационного процесса.

4. Предложить принципы оптимизации программы реабилитации путём структурирования и использования психофизиологических конструктов воздействия на комфорт жизни.

Общее количество включенных в исследование пациентов составило 180, находившиеся в остром периоде нарушения мозгового кровообращения. Проходившие обследование и лечение стационарно. Длительность нарушения составил от трех до 16 дней. Были взяты пациенты от 48 до 65 лет с геморрагическими и ишемическими формами инсульта, подтвержденными нейровизуальными и клиническими способами. Среди них 60 пациентов, перенесших левополушарный инсульт, и 60 пациентов, перенесших правополушарный инсульт. Контрольную группу пациентов составили больные, в количестве 60 человек, которые не проходили реабилитационные мероприятия, получали только симптоматическое лечение.

Критерия для исключения и препятствующие реабилитационной работе явились выраженные когнитивные нарушения, тотальная афазия, а также эпилептического синдрома. Исследование проводилось в ранний реабилитационный период. Согласие на психологическое исследование было получено отдельно у каждого [5, с. 33].

В процессе ранней реабилитации в условиях стационара перенесших острое нарушение мозгового кровообращения использовали комплекс по психологическому консультированию, психологической коррекции, релаксационные упражнения с применением аутогенной тренировки, активно применяли БОС - терапию. Занятия поводились как в индивидуальной, так и групповой форме.

Эффективность оценивалась в течении двух недель, анализируя до и после прохождения мероприятий.

Методы исследования. Состояние функций центральной нервной системы оценивалось с помощью классических методов пато- и нейропсихологического исследования. Использовалась методика краткая шкала оценки психического статуса (MMSE), анкетирование динамики жалоб. Изучение эмоциональной сферы проводилась при помощи HADS (госпитальной шкалы оценки тревоги и депрессии), методики реактивной тревожности Спилбергера - Ханина $[4,9]$.

Статистический анализ расчетов достоверности различий производился с применением Хи - квадрат Пирсона, который проверяет значимость расхождения эм- пирических от теоретических, с использованием пакета «Статистика» Microsoft Excel.

Проводился сравнительный анализ показателей, полученных при изучении пациентов с левополушарной и правополушарной локализацией очага поражения. Исследование распределения статистики.

Результаты исследования Анкетирование. До начала терапии, у пациентов, с пострадавшим левым полушарием (далее ЛП) из 60 человек жалобы предъявляли 47. После терапии - 29 человек. Практически в 2 раза снижение жалоб.

До начала терапии, у пациентов, с пострадавшим правым полушарием (далее ПП) из 60 человек жалобы предъявляли 45 человек. После терапии - 26 человека.

Жалобы на нарушение сна:

- в группе ЛП, до терапии - 18 человек. После - 15 человек. Не значительный положительный эффект;

- в группе ПП, до терапии - 36. После - 22 человека. Достаточно значительная положительная динамика, которая качественно влияет на качество жизни;

- в контрольной группе, до терапии - 23. После - 21 человек. Не значительная динамика, связанная с субъективной оценкой.

Нарушение памяти:

- в группе ЛП, до терапии - 47. После - 36 человек. За 14 дней улучшение высшей нервной деятельности (далее ВНД) у 9 человек - отличный результат;

- в группе ПП, до терапии - 32. После - 27 человек. Не такая хорошая динамика, но она положительная, что делает прогноз на реабилитацию лучшим;

- в контрольной группе, до терапии - 30, после - 19 человек. Значительный прогресс.

Эмоциональный фон:

- в группе ЛП, до терапии и после терапии статистически значимых результатов не обнаружено. Большая часть исследуемых была в стабильном эмоциональном фоне - 42 человека. После - 45- в группе ПП, до терапии было всего лишь 25 человек со стабильным эмоциональным фоном, а с пониженным 29 человек. После терапии - 53 человека со стабильным и лишь 7 со сниженным.

В контрольной группе не удалось получить значимых результатов, пациенты из сниженного эмоционального состояния перешли в категорию повышенного эмоционального состояния.

Жалобы на головные боли:

- в группе ЛП, до терапии - 13 человек. После - 3;

- в группе ПП, до терапии - 20 человек. После - 1. 
В контрольной группе не удалось получить показательных результатов.

Значительный прогресс в плане снятия болевого синдрома, что позволяет пациентам не отвлекаться и не концентрироваться на болях. Быть в тонусе и сохранять позитивный настрой. Также пациенты сразу отмечают эффект от лечения и могут надеяться на выздоровление.

Из данных анкетирования получается, что с пациентами необходимо работать практически сразу, чем раньше начинать терапию, тем лучше результаты. Считаем, что важно внимательно относиться ко всем указанным пара- метрам, не забывая, что пациент может зафиксироваться на своих жалобах и будет проблематично работать с ним дальше. Результаты методики MMSE приведены в таблице1.

Как видно из данных таблицы 1 - отмечается улучшение когнитивных способностей у пациентов с поражением ЛП более чем в 2 раза. Но что важнее, из группы преддеменционных нарушений значительное количество пациентов «переведено» в первую группу.

Результаты методики исследования реактивной тревожности Спилбергера - Ханина приведены в таблице 2.

Таблица 1

Результаты методики MMSE

\begin{tabular}{|c|c|c|c|c|c|c|}
\hline \multirow[t]{2}{*}{ ПДО MМSE } & \multicolumn{2}{|c|}{ ЛП (до), $\mathrm{n}=60$ чел } & \multicolumn{2}{|c|}{ ЛП (через 14 дней), n=60 чел } & \multirow[t]{2}{*}{ Хи-кв. } & \multirow[t]{2}{*}{ р-уров. } \\
\hline & $n$ & $\%$ & $n$ & $\%$ & & \\
\hline Нет нарушений & 8 & 13,3 & 39 & 65 & \multirow[t]{2}{*}{33,61} & \multirow[t]{2}{*}{0,01} \\
\hline Преддем.когн. нарушения & 52 & 86,7 & 21 & 35 & & \\
\hline \multirow[t]{2}{*}{ ПДО MMSE } & \multicolumn{2}{|c|}{ ПП (до), $\mathrm{n}=60$ чел } & \multicolumn{2}{|c|}{ ПП (через 14 дней), n=60 чел } & \multirow[t]{2}{*}{ Хи-кв. } & \multirow[t]{2}{*}{ р-уров. } \\
\hline & $n$ & $\%$ & $n$ & $\%$ & & \\
\hline Нет нарушений & 24 & 40 & 31 & 51,6 & \multirow[t]{2}{*}{1,64} & \multirow[t]{2}{*}{0,20} \\
\hline Преддем.когн. нарушения & 36 & 60 & 29 & 48,4 & & \\
\hline \multirow[t]{2}{*}{ ПДО MМSE } & \multicolumn{2}{|c|}{ Контроль (до), $\mathrm{n}=60$ чел } & \multicolumn{2}{|c|}{ Контроль (через 14 дней), n=60 чел } & \multirow[t]{2}{*}{ Хи-кв. } & \multirow[t]{2}{*}{ р-уров. } \\
\hline & $n$ & $\%$ & $\mathrm{n}$ & $\%$ & & \\
\hline Нет нарушений & 8 & 13,3 & 11 & 18,3 & \multirow[t]{2}{*}{0,56} & \multirow[t]{2}{*}{0,45} \\
\hline Преддем.когн. нарушения & 52 & 86,7 & 49 & 81,7 & & \\
\hline
\end{tabular}

Результаты методики исследования реактивной тревожности Спилбергера - Ханина

\begin{tabular}{|c|c|c|c|c|c|c|}
\hline \multirow[t]{2}{*}{ Реактивная тревожность } & \multicolumn{2}{|c|}{ ЛП (до), $\mathrm{n}=60$ чел } & \multicolumn{2}{|c|}{ ЛП (через 14 дней), n=60 чел } & \multirow[t]{2}{*}{ Хи-кв. } & \multirow[t]{2}{*}{ p-уров } \\
\hline & $n$ & $\%$ & $\mathrm{n}$ & $\%$ & & \\
\hline Низкий уровень & 19 & 31,6 & 35 & 58,3 & 8,60 & 0,04 \\
\hline Умеренный ур. & 31 & 51,7 & 24 & 40 & 1,64 & 0,20 \\
\hline Высокий уровень & 10 & 16,7 & 1 & 1,6 & 8,10 & 0,01 \\
\hline \multirow[t]{2}{*}{ Реактивная тревожность } & \multicolumn{2}{|c|}{ ПП (до), n=60 чел } & \multicolumn{2}{|c|}{ ПП (через 14 дней), $n=60$ чел } & \multirow[t]{2}{*}{ Хи-кв. } & \multirow[t]{2}{*}{ р-уров. } \\
\hline & $n$ & $\%$ & $\mathrm{n}$ & $\%$ & & \\
\hline Низкий уровень & 36 & 60 & 43 & 71,7 & 1,82 & 0,18 \\
\hline Умеренный ур. & 19 & 31,7 & 12 & 20 & 2,13 & 0,14 \\
\hline Высокий уровень & 5 & 8,3 & 5 & 8,3 & 0,00 & 1,00 \\
\hline \multirow[t]{2}{*}{ Реактивная тревожность } & \multicolumn{2}{|c|}{ Контроль (до), $\mathrm{n}=60$ чел } & \multicolumn{2}{|c|}{ Контроль (через 14 дней), n=60 чел } & \multirow[t]{2}{*}{ Хи-Кв. } & \multirow[t]{2}{*}{ р-уров. } \\
\hline & $\mathrm{n}$ & $\%$ & $\mathrm{n}$ & $\%$ & & \\
\hline Низкий уровень & 17 & 28,4 & 26 & 43 & 2,94 & 0,09 \\
\hline Умеренный ур. & 32 & 53,3 & 30 & 50 & 0,13 & 0,72 \\
\hline Высокий уровень & 11 & 18,3 & 4 & 7 & 3,73 & 0,05 \\
\hline
\end{tabular}


Также пациенты с поражением ЛП как и контрольная группа, после терапии снизили свое присутствие из группы высокого уровня по реактивной тревожности. То есть качество жизни, оценка происходящего вокруг для таких пациентов становится лучше и понятнее. Снижение стресса также важно для пациентов, которые перенесли ОНМК.

Результаты методики исследования уровня тревоги и депрессии (по шкале HADS) приведены в таблицах 3 и 4.
Опять же пациенты с поражением ЛП показывают лучший результат, количество человек в группе «норма» выросло значительно. Также снижение в группе выраженного уровня тревоги и депрессии позволяет специалистам рассматривать их как вне группы риска по суицидальным мыслям, не желании работать над собой и справляться с жизненными ситуациями.

Клинически выраженная группа депрессии у пациен-

Таблица 3

Результаты методики исследования уровня тревоги и депрессии (по шкале HADS)

\begin{tabular}{|c|c|c|c|c|c|c|}
\hline \multirow[t]{2}{*}{ HADS шкала тревоги } & \multicolumn{2}{|c|}{ ЛП (до), $\mathrm{n}=60$ чел } & \multicolumn{2}{|c|}{ ЛП (через 14 дней), n=60 чел } & \multirow[t]{2}{*}{ Хи-кв. } & \multirow[t]{2}{*}{ р-уров. } \\
\hline & $\mathrm{n}$ & $\%$ & $\mathrm{n}$ & $\%$ & & \\
\hline Норма & 3 & 5,4 & 29 & 48,6 & 28,81 & 0,01 \\
\hline Субклинически - выраж. & 47 & 78,4 & 29 & 48,6 & 11,6 & 0,01 \\
\hline Клинически - выраж. & 10 & 16,2 & 2 & 2,7 & 5,93 & 0,01 \\
\hline \multirow[t]{2}{*}{ HADS шкала тревоги } & \multicolumn{2}{|c|}{ ПП (до), $\mathrm{n}=60$ чел } & \multicolumn{2}{|c|}{ ПП (через 14 дней), n=60 чел } & \multirow[t]{2}{*}{ Хи-Кв. } & \multirow[t]{2}{*}{ р-уров. } \\
\hline & $n$ & $\%$ & $n$ & $\%$ & & \\
\hline Норма & 28 & 46,5 & 36 & 60,5 & 2,14 & 0,14 \\
\hline Субклинически - выраж. & 29 & 48,8 & 20 & 32,5 & 2,79 & 0,10 \\
\hline Клинически - выраж. & 3 & 4,7 & 4 & 7 & 0,15 & 0,70 \\
\hline \multirow[t]{2}{*}{ HADS шкала тревоги } & \multicolumn{2}{|c|}{ Контроль (до), n=60 чел } & \multicolumn{2}{|c|}{ Контроль (через 14 дней), n=60 чел } & \multirow[t]{2}{*}{$\overline{X и-К в . ~}$} & \multirow[t]{2}{*}{$\overline{\text { р-уров. }}$} \\
\hline & $n$ & $\%$ & $n$ & $\%$ & & \\
\hline Норма & 17 & 28,1 & 21 & 34,4 & 0,62 & 0,43 \\
\hline Субклинически - выраж. & 36 & 59,4 & 28 & 46,85 & 2,14 & 0,14 \\
\hline Клинически - выраж. & 8 & 12,5 & 11 & 18,75 & 0,56 & 0,45 \\
\hline
\end{tabular}

Результаты методики исследования уровня тревоги и депрессии (по шкале HADS)

\begin{tabular}{|c|c|c|c|c|c|c|}
\hline \multirow[t]{2}{*}{ HADS шкала депрессии } & \multicolumn{2}{|c|}{ ЛП (до), $\mathrm{n}=60$ чел } & \multicolumn{2}{|c|}{ ЛП (через 14 дней), $n=60$ чел } & \multirow[t]{2}{*}{ Хи-кв. } & \multirow[t]{2}{*}{ р-уров. } \\
\hline & $n$ & $\%$ & $\mathrm{n}$ & $\%$ & & \\
\hline Норма & 16 & 27 & 21 & 35,5 & 0,98 & 0,32 \\
\hline Субклинически - выраж. & 36 & 59,5 & 39 & 64,5 & 0,32 & 0,57 \\
\hline Клинически - выраж. & 8 & 13,5 & 0 & 0 & - & - \\
\hline \multirow[t]{2}{*}{ HADS шкала депрессии } & \multicolumn{2}{|c|}{ ПП (до), $\mathrm{n}=60$ чел } & \multicolumn{2}{|c|}{ ПП (через 14 дней), n=60 чел } & \multirow[t]{2}{*}{ Хи-кв. } & \multirow[t]{2}{*}{ р-уров. } \\
\hline & $\mathrm{n}$ & $\%$ & $\mathrm{n}$ & $\%$ & & \\
\hline Норма & 22 & 37,2 & 29 & 47,6 & 1,67 & 0,20 \\
\hline Субклинически - выраж. & 27 & 44,2 & 29 & 49 & 0,13 & 0,71 \\
\hline Клинически - выраж. & 11 & 18,6 & 3 & 4,7 & 5,17 & 0,02 \\
\hline \multirow[t]{2}{*}{ HADS шкала депрессии } & \multicolumn{2}{|c|}{ Контроль (до), $\mathrm{n}=60$ чел } & \multicolumn{2}{|c|}{ Контроль (через 14 дней), n=60 чел } & \multirow[t]{2}{*}{ Хи-Кв. } & \multirow[t]{2}{*}{ р-уров. } \\
\hline & $n$ & $\%$ & $\mathrm{n}$ & $\%$ & & \\
\hline Норма & 30 & 50 & 31 & 51,2 & 0,03 & 0,86 \\
\hline Субклинически - выраж. & 23 & 37,5 & 19 & 31,25 & 0,59 & 0,44 \\
\hline Клинически - выраж. & 8 & 12,5 & 11 & 18,75 & 0,57 & 0,45 \\
\hline
\end{tabular}


тов с пострадавшим ПП стала меньше, то есть мы получаем так же возможность не относить пациентов к группе высокого риска по суициду, не желании работать и получать лечение.

\section{Выводы}

По результату нашей работы, можно утверждать, что нововведения психологической реабилитации абсолютно необходима пациентам, перенесшим инсульт. Сравнительно не большой срок работы с пациентами (14 дней) позволил оценить положительную динамику от работы с пациентами. Необходимо расширять данное исследование, чтобы была возможность работать с пациентами дольше, чем 14 дней. Такие пациенты нуждаются в постоянной работе с психологами, как индивидуально, так и групповая терапия. Так же важна работа всех других специалистов, как физиотерапевтов, логопедов.

Важно понимать, что необходимо начинать работу с пациентами сразу в остром периоде инсульта, пока эффективность от встраивания психофизиологических конструктов наиболее высока.

\section{ЛИТЕРАТУРА}

1. Ахутина, Т.В. Клинико-психологическая диагностика и клинико-психологическая реабилитация пациентов с нарушениями памяти при повреждениях головного мозга / Т.В. Ахутина, Н.А. Варако, Ю.П. Зинченко и др. // Consilium medicum. - 2016. - Т. 18, № 2.1. - С. 68-81.

2. Балунов, 0.А. Факторы, определяющие устойчивость уровня реабилитации постинсультных больных: метод. рекомендации / 0.А. Балунов, Т.Д. Демиденко. - СПб. : Изд-во С.-Петерб. психоневрол. науч.-исслед. ин-та им. В.М. Бехтерева, 2015. - 16 с.

3. Балунов, 0.А. Динамика очаговых неврологических нарушений у больных, перенесших инсульт / 0.А. Балунов, Я.Н. Кушнеренко // Журнал неврологии и психиатрии им. С.С. Корсакова. - 2016. - № 5. Т. 101. - С. 4-8.

4. Белова, А.Н. Шкалы, тесты, опросники в медицинской реабилитации / А.Н. Белова, О.Н. Щепетова. - М. : Антидор, 2016. - 440 с.

5. Белова, А.Н. Нейрореабилитация / А.Н. Белова // Руководство для врачей. - 2-е изд. - М. : Антидор, 2017. - 1288 с.

6. Демиденко, Т.Д. Основы реабилитации неврологических больных / Т.Д. Демиденко, Н.Г. Ермакова. - СПб. : Фолиант, 2014. - 304 с.

7. Ермакова, Н.Г. Психологические особенности больных с последствиями инсульта в левом и правом полушарии головного мозга в процессе реабилитации / Н.Г. Ермакова // Вестн. С. -Петерб. ун-та. Медицина. - 2018. - Вып. 3. - С. $24-32$.

8. Ермакова Н.Г. Психологическая кор ᄀрекция самоотношения у больных с когнитивными нарушениями после инсульта / Н.Г.Ермакова // Известия Российского государственного педагогического университета им. А.И. Герцена. - 2017. - № 167. - С. 90-103.

9. Ермакова Н.Г. Психологическая реабилитация больных с последствиями инсульта в условиях восстановительного лечения // Медицинская психология в России. - 2018. - Т. 10, №2. -9 с.

10. Рубинштейн, С.Я. Эксперименталь ᄀные методы патопсихологии и опыт их применения в клинике / С.Я. Рубинштейн. - 3-е изд. - М. : Изд-во Института психотерапии, 2017. - 384 с.

11. Чуканова, Е.И. Хроническая ишемия мозга, нейропластичность, возможности терапии /Е.И. Чуканова, А.С. Чуканова //Неврология, нейропсихиатрия, психосоматика. - 2017. - 9(2). - C. 102-107. DOI: 10.14412/2074-2711-2017-2-102-107

12. Thomas, S.A. Predictors of emotional distress after stroke / S.A. Thomas, N.B. Lincoln // Stroke. - 2018. - 39(4). - P. 1240-1245. 